\title{
北祁连东草河蛇绿岩: 一个早古生代的洋壳残片
}

\author{
曾建元 ${ }^{\oplus} \quad$ 杨怀仁 ${ }^{\oplus^{*}}$ 杨宏仪 ${ }^{\oplus}$ 刘敦一 ${ }^{\circledR}$ 蔡金郎 ${ }^{\circledR}$ 吴汉泉 ${ }^{\circledR}$ 左国朝 ${ }^{\circledR}$ \\ (1) 成功大学地球科学系, 台南 701; (2) 中国地质科学院地质研究所, 北京离子探针中心, 北京 100037; (3) 西安地质矿产研究所, \\ 西安 710054; (4) 甘肃地质调查局, 兰州 730000.* 联系人,E-mail: hjyang@mail.ncku.edu.tw)
}

\begin{abstract}
摘要 位于北祁连山俯冲杂岩带南面的东草河蛇绿岩是一个构造移置岩块 (大小为 $3 \mathrm{~km} \times 6 \mathrm{~km}$ ). 其下 部岩石组合为多期次侵入的岩床状堆晶纯檄岩-橄长岩-斜(钙)长岩-斜(钙)长质辉长岩-辉长岩系列, 其 中可见不谐合的纯橄岩-橄长岩侵入体. 往上过渡到均质的辉长岩-苏长质辉长岩系列, 顶部则有辉绿岩 质岩墙与玄武岩质熔岩. 矿物结晶顺序为橄榄石士铬尖晶石 $\rightarrow$ 斜长石 $\rightarrow$ 单斜辉石 $\rightarrow$ 斜方辉石 $\rightarrow$ 钛铁氧化 物矿物. 堆晶岩中的铬尖晶石成分(Mg\#: 42-66, Cr\#: 41-57)类似于现今的洋壳特征. 堆晶岩石与均质岩 石系列中的斜长石与单斜辉石成分变化, 反映了岩浆结晶分异的过程且与现今的洋壳成分特征相似. 辉绿-玄武质熔岩的全岩地球化学成分与 N-MORB 类似. 东草河蛇绿岩组成岩石群的 REE 与微量元素 蛛网图分布特征显示它们是 N-MORB 岩浆分异的结果. 利用 SHRIMP 铅石 U-Pb 定年法, 获得苏长质辉 长岩的锆石 ${ }^{206} \mathrm{~Pb} /{ }^{238} \mathrm{U}$ 加权平均年龄为 (497士 7) Ma, 代表东草河蛇绿岩的构造侵位年龄. 由岩石建造、 矿物化学、全岩地球化学与定年学的研究结果, 可以确认东草河蛇绿岩是一个古祁连洋洋壳残片, 为古 祁连洋向北俯冲的一个重要标志.
\end{abstract}

关键词 蛇绿岩 北祁连 洋壳 东草河

蛇绿岩是海洋岩石圈的残片 $[1]$, 是产于洋盆扩 张脊的洋壳+地幔的岩石组合 ${ }^{[2]}$. 中国蛇绿岩岩石组 合的保存情况，差异相当大，通常是以蛇绿混杂岩的 形式产出, 罕见岩石组合发育齐全且具层序性的蛇 绿岩 [2]. 最近, 我们在野外岩石建造、岩相学与地球 化学研究的基础上, 在北祁连造山带的俯冲杂岩带 南面东草河上游发现保存完整的洋壳残片, 并命名 为东草河蛇绿岩. 本文在对其野外关系、矿物化学、 全岩地球化学和年代学研究的基础上, 讨论了东草 河蛇绿岩形成的构造环境及潜在的地质意义.

\section{1 地质背景及野外产状}

北祁连造山带是一个典型的加里东造山带, 它 保存有完整的早古生代板块构造记录, 是研究中国 古板块体制的最佳造山带之一 ${ }^{[3 \sim 6]}$.

传统上北祁连造山带的古板块体制被认为具有 典型脊-沟-弧-盆体系特征 ${ }^{[6]}$. 在其中段, 古岛弧火山 岩带主要沿走廊南山分布 ${ }^{[3,7]}$. 其南侧出露有俯冲杂 岩 ${ }^{[8 \sim 10]}$ (包括蓝片岩和低温榴辉岩)和蛇绿岩片 ${ }^{[3,7]}$. 北侧为弧后盆地, 主要由早古生代的火山-沉积岩系 和蛇绿岩所组成 ${ }^{[6,7]}$. 其基本的地质构造格架如图 1(a)
所示.

东草河蛇绿岩出露于祁连县南 $20 \mathrm{~km}$ 的火山岩 带中(图 1(b)). 属于北祁连俯冲杂岩带南面托莱山蛇 绿岩带的一部分. 它是一个构造移置岩块 (大小为 3 $\mathrm{km} \times 6 \mathrm{~km})$, 夹在早古生代的沉积- 火山岩系中. 根据 野外产状, 可将东草河蛇绿岩的岩石组合划分作 3 个 单元: (i ) 堆晶纯檄岩-檄长岩-斜(钻)长岩-斜(钙)长 质辉长岩-辉长岩系列, 明显是由多期次侵入的岩床 组合而成, 底部由堆晶纯橄岩-橄长岩所组成, 反映 的是橄榄石与斜长石堆晶作用的结果, 往上则为具 有堆晶条带的钙长质辉长岩(图 2(a)). 堆晶条带主要 是不同比例的浅色斜长石与暗色辉石所构成, 组合 岩性为堆晶钙长岩-钙长质辉长岩-辉长岩. 堆晶岩系 中也经常见到大小不一(长约 1 500 m) 的不谐合的纯 橄岩-橄长岩侵入体(discordant dunite-troctolite intrusive bodies). (ii) 均质辉长岩系列, 主要由辉长岩-苏 长质辉长岩所构成, 辉绿状岩脉则经常穿插其间. 堆晶 辉长岩与均质辉长岩系列的界线是渐变的. 界线附 近的堆晶辉长岩主要呈现岩脉状结构, 穿插在均质 辉长岩中. (iii) 顶部主要由辉绿岩质岩墙(图 2(b))与 玄武岩质熔岩所构成, 结构上来看似乎是由均质辉 

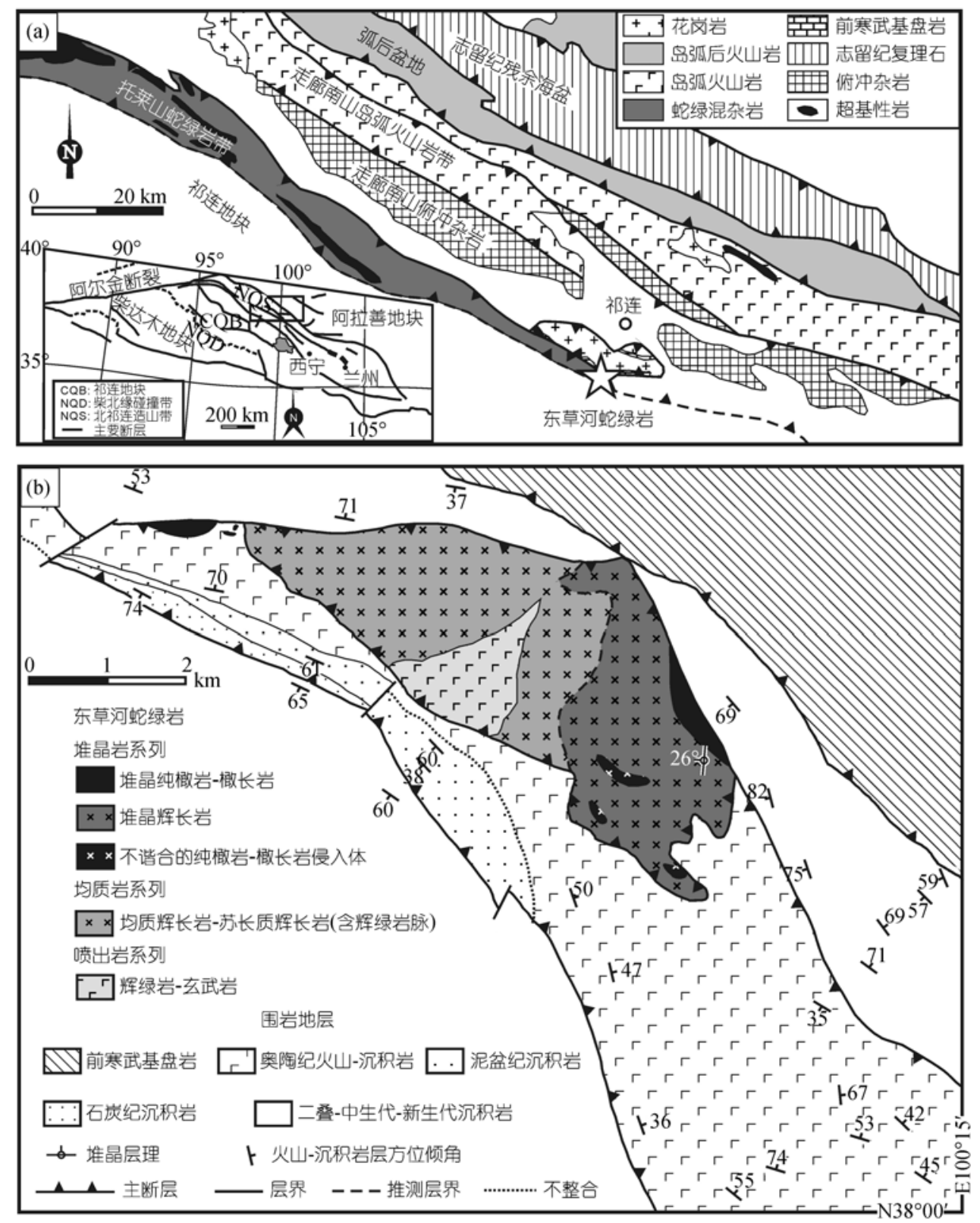

图 1

(a) 北祁连造山带中段的地质构造分带, 星号处为东草河蛇绿岩的位置; (b) 东草河蛇绿岩的地质产状图

长岩分异而出的熔体固结而成. 整体上, 东草河蛇绿 岩并没有遭受明显的变形作用.

\section{2 岩相学}

整体而言, 东草河蛇绿岩只经历洋底热水变质 作用, 没有后期区域变质作用的叠加. 堆晶纯橄岩橄长岩的主要堆晶相为橄榄石和铬尖晶石, 斜长石 与单斜辉石则为填隙相(图 2(c)), 由于洋底热水变质 作用的影响, 只有铬尖晶石与少量的单斜辉石残存.
部分堆晶橄长岩则是由橄榄石与斜长石的堆晶构成 (图 2(d)), 单斜辉石仍为填隙相, 显然斜长石早于单 斜辉石晶出. 堆晶钙长岩-钙长质辉长岩-辉长岩则是 由不同比例的堆晶斜长石和单斜辉石构成，在野外 则呈现韵律的堆晶结构. 部分的堆晶辉长岩则出现 嵌晶结构, 数个自形晶状的斜长石被包裹于单斜辉 石中.

均质辉长岩系列相对堆晶纯橄岩-辉长岩系列新 

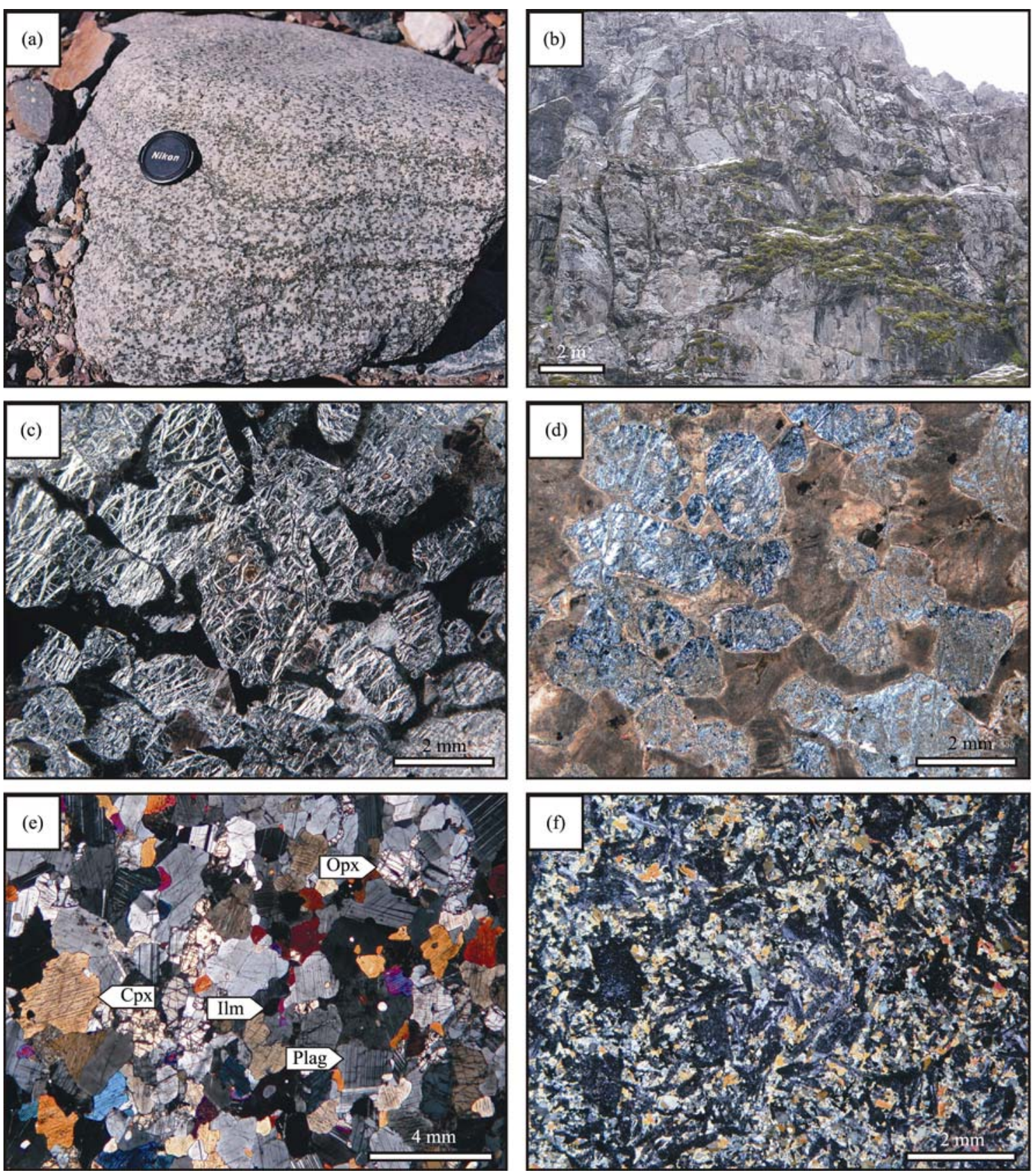

图 2

(a) 堆晶的钙长质辉长岩; (b) 岩墙状(单个岩墙宽度约 $2 \mathrm{~m}$ )的辉绿岩; (c) 堆晶纯橄岩, 堆晶橄榄石已蛇纹石化, 填隙的斜长石则已蚀变成 钻铝榴石; (d) 堆晶橄长岩, 堆晶橄榄石已蚀变成灰黑色的蛇纹石, 填隙和堆晶的斜长石则已蚀变成黄灰色的葡萄石; (e) 均质苏长质辉长 岩的岩相, 矿物名缩写为 Cpx: 单斜辉石, Opx: 斜方辉石, Plag: 斜长石, Ilm: 钛铁矿; (f) 辉绿岩

鲜, 没有明显的蚀变结构. 主要岩石有辉长岩和苏长质 辉长岩, 两者的差异在于斜方辉石的有无. 苏长质辉长 岩主要矿物相为斜长石、单斜辉石、斜方辉石和钛铁氧 化物矿物, 不含橄榄石(图 2(e)). 部分苏长质辉长岩含 有普通角闪石, 可能是热水作用所致 [11]. 某些角闪石 则成为主要矿物相, 组成角闪辉长岩. 具有辉绿结构的
辉绿岩质岩墙(图 2(f)) 与玄武岩质熔岩, 是由经历辉长 岩质堆晶作用的熔体冷却形成, 岩相上主要是由细粒 的辉石、斜长石与钛铁氧化物矿物构成, 然而大部分已 经历海水蚀变, 只有部分岩块可见残余的单斜辉石.

由岩石系列与堆晶矿物相的出现顺序, 可以清 楚反映矿物结晶顺序为橄榄石土铬尖晶石 $\rightarrow$ 斜长石 $\rightarrow$ 
单斜辉石 $\rightarrow$ 斜方辉石 $\rightarrow$ 钛铁氧化物矿物. 这个结晶 顺序为典型的洋壳矿物结晶顺序 [12].

\section{3 矿物化学}

矿物的电子探针分析在成功大学地球科学系完 成. 所用的扫描电子显微镜型号为 JEOL JSM-840A, 探针分析的软件型号为 Oxford ISIS 300 series. 分析 条件为加速电压 $20 \mathrm{kV}$, 电流 $400 \mathrm{pA}$, 电子束斑大小 约 $2 \mu \mathrm{m}$. 并利用光学显微镜对焦以确保固定的工作 距离. 天然矿物与合成物质之元素能量频谱作为定 量标准. 金属钴则用作随机测量的校正标准.

\section{1 铬尖晶石}

铬尖晶石(成分见网络版附录 1)仅出现在堆晶纯 橄岩-橄长岩-钙长质辉长岩与不谐和的纯橄岩-橄长岩 中. 堆晶纯橄岩-橄长岩中铬尖晶石 $\mathrm{Mg} \#$ 值为 42 66,
$\mathrm{Cr} \#$ 值为 41 57, 并且具有低的 $\mathrm{Fe}^{3+} \#$ 与 $\mathrm{TiO}_{2}$ (图 3(a),

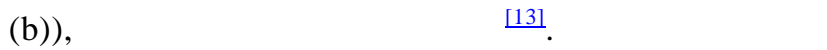
岩中的铬尖晶石成分则比堆晶纯橄岩-橄长岩中铬尖 晶石有稍低的 $\mathrm{Mg} \#$ 值, 两者成分大致相似. 不谐和纯 橄岩-橄长岩中的铬尖晶石明显有两种成分(图 3(a), (b)), 并且可以在薄片尺度同时存在. 棕红色铬尖晶 石的 Cr\#值稍低于堆晶纯橄岩-橄长岩-钙长质辉长岩, 代表原生熔体的铬尖晶石成分. 而不透明的铬尖晶 石成分上明显高 $\mathrm{Cr} \#, \mathrm{Fe}^{3+} \#$ 和 $\mathrm{TiO}_{2}$, 代表此原生熔体 与围岩同化混染作用后新结晶的铬尖晶石 ${ }^{[14 \sim 16]}$.

\section{2 辉石}

总体上, 单斜辉石的成分 (见网络版附录 2)变化 可以反映结晶分异的趋势, 并且与洋壳结晶分异的趋 势相似(图 4(a) (d) $)^{[17]}$. 单斜辉石中 $\mathrm{Cr}_{2} \mathrm{O}_{3}$ 变化, 在堆 晶辉长岩形成之后( Mg\# < 88)含量明显下降, 反映铬
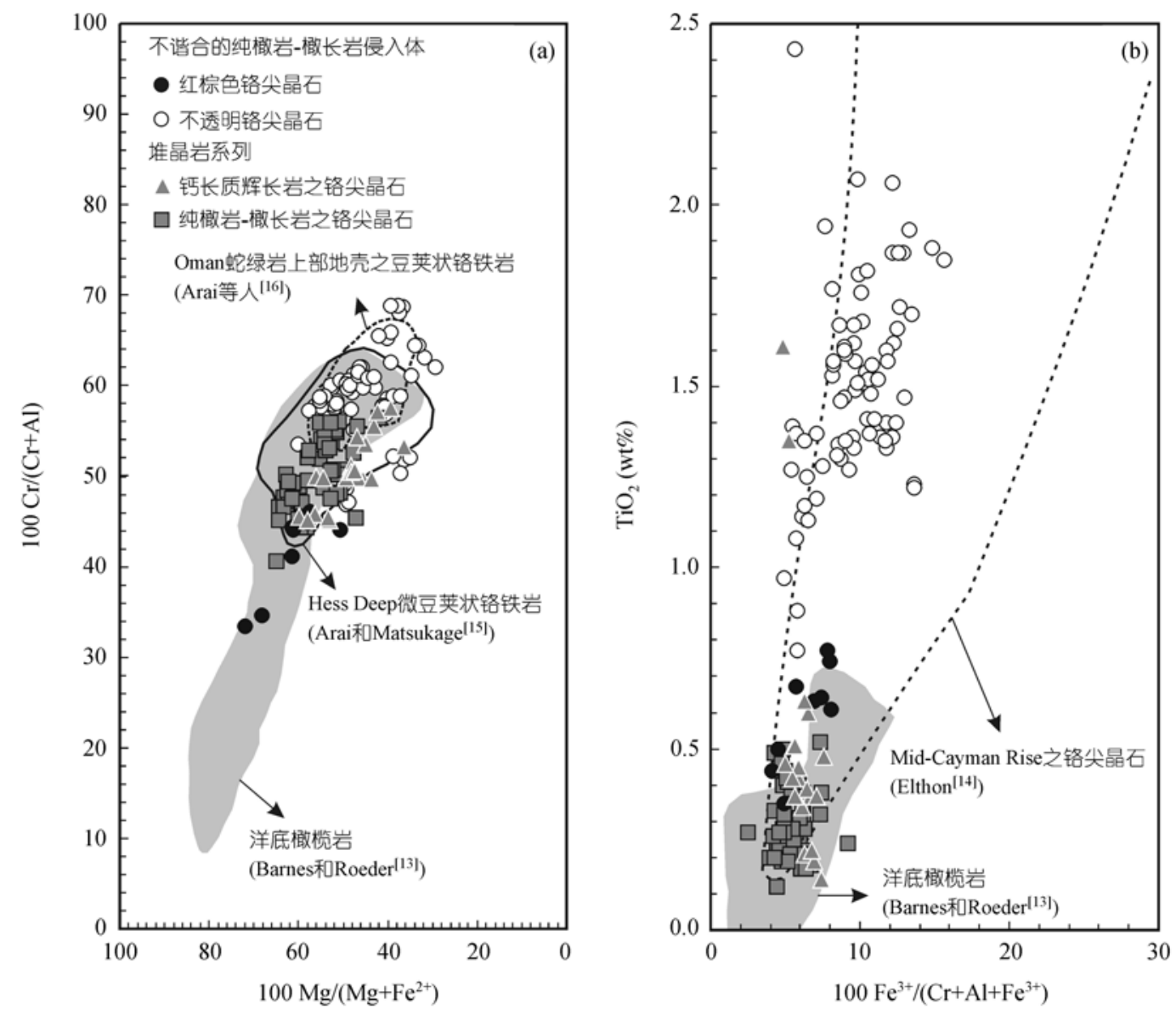

图 3

(a) 铬尖晶石的 Cr\#-Mg\#图; (b) 铬尖晶石的 $\mathrm{Fe}^{3+} \#-\mathrm{TiO}_{2}$ 图. 堆晶纯橄岩-橄长岩的铬尖晶石成分主要分别落入(a)和(b)图中的灰色阴影的洋底橄榄 岩区域. 而不谐和纯橄岩-橄长岩中不透明的铬尖晶石成分明显与堆晶纯橄岩-橄长岩不同, 成因如本文所述 


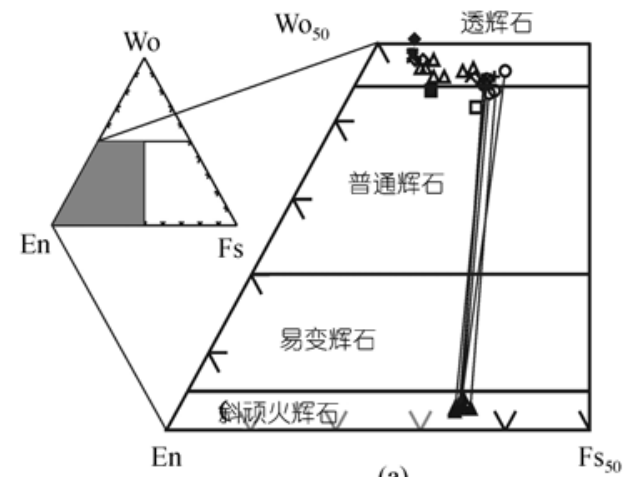

(a)

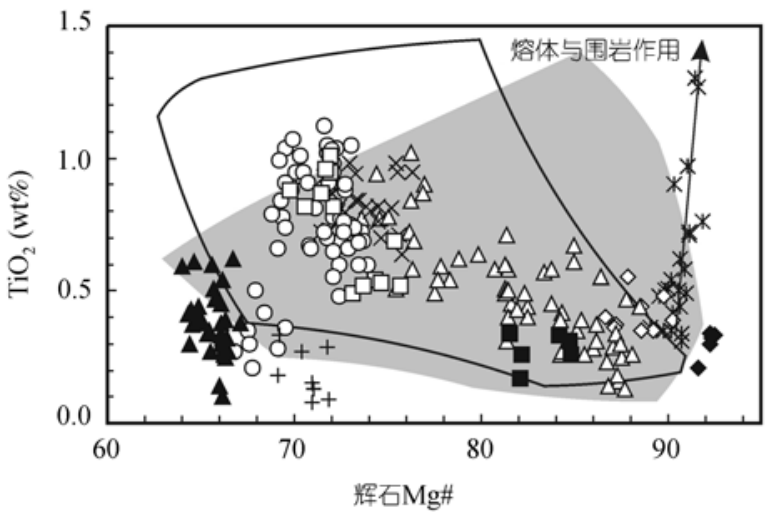

(c)

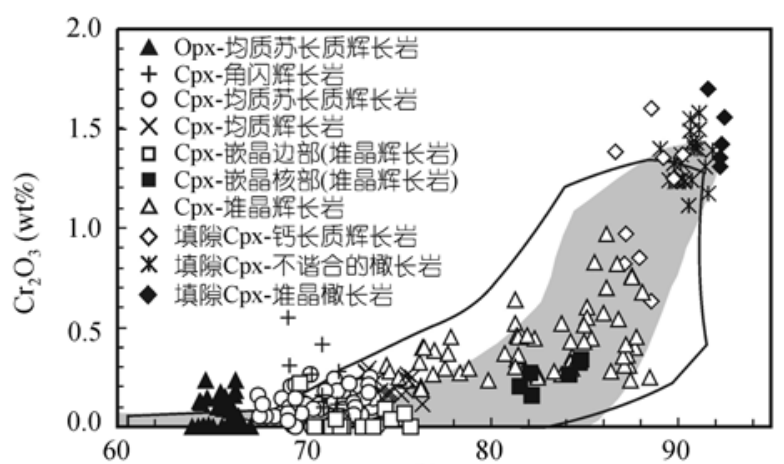

(b)

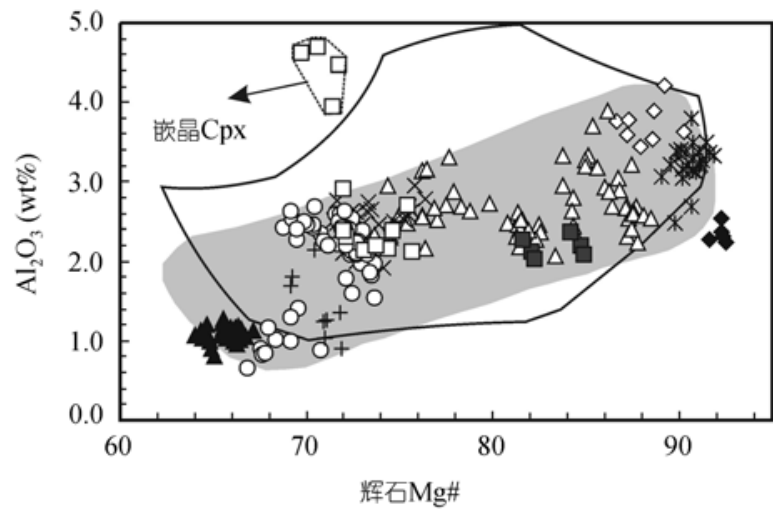

(d)

图 4

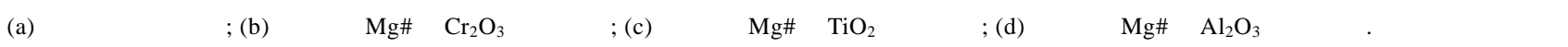
洋性堆晶辉石的成分, 实线范围则是洋中脊玄武岩的辉石斑晶与在 1 标准大气压下实验的辉石成分

尖晶石晶出之后消耗岩浆中大量Cr元素(图 4(b)). $\mathrm{TiO}_{2}$ 的含量变化则是随着结晶分异作用而增加, 直到钛铁 氧化物矿物晶出后, 导致部分晚期结晶的苏长质辉长 岩与角闪石辉长岩(两者单斜辉石之 $\mathrm{Mg} \#$ 约 $<70$ )中的 $\mathrm{TiO}_{2}$ 含量下降(图 4(c)). 不谐合纯檄岩-檄长岩中的 $\mathrm{TiO}_{2}$ 的含量变化则与结晶分异作用无关, 而是反映熔 体与围岩作用的结果 ${ }^{[18,19]}$. $\mathrm{Al}_{2} \mathrm{O}_{3}$ 的含量变化主要反映 斜长石晶出对岩浆化学成分的影响, 斜长石晶出会消 耗岩浆中的 $\mathrm{Al}_{2} \mathrm{O}_{3}$ 成分, 造成晚期结晶的单斜辉石 $\mathrm{Al}_{2} \mathrm{O}_{3}$ 成分降低(图 4(d)). 具嵌晶结构高铝成分的单斜 辉石则是因填隙的晶核在后堆晶作用中成长而成 [201(图 4(d)). 斜方辉石的成分变化见图 4(a) (d)中.

\section{3 斜长石}

从堆晶钙长质辉长岩 $\rightarrow$ 堆晶辉长岩 $\rightarrow$ 均质辉长 岩 $\rightarrow$ 均质苏长质辉长岩 $\rightarrow$ 角闪辉长岩中的斜长石An值 变化(矿物成分见网络版附录 3), 大致为 $\mathrm{An}_{990} \rightarrow \mathrm{An}_{88-63}$ $\rightarrow \mathrm{An}_{68-58} \rightarrow \mathrm{An}_{66-54} \rightarrow \mathrm{An}_{56-50}$. 通常认为高水压环境, 如岛弧环境, 结晶之斜长石具有的高 $A n$ 值 $(A n>$ $75)^{[21]}$. 所以典型岛弧环境的Troodos蛇绿岩, 其晶出
的斜长石An值较高(图 5) ${ }^{[22]}$. 从东草河蛇绿岩的斜长 石与单斜辉石的成分变化来看, 与现今洋壳(例如东 太平洋中洋脊Hess Deep) ${ }^{[23]}$ 的成分十分类似(图 5).

\section{4 全岩地球化学}

选定 8 个代表性岩石进行全岩地球化学的分析, 它们分别为堆晶橄长岩、钻长质辉长岩、辉长岩, 均 质苏长质辉长岩, 玄武岩和辉绿岩. 测试是委托美国华 盛顿州立大学地质系地质分析实验室(Geoanalytical Laboratory, Washington State University, USA)完成. 主要元素与部分微量元素用 $X$ 射线苂光光谱法 $(X R F)$ 测定, 微量元素则用酸溶等离子质谱法(ICP-MS)测 定. 测试结果见表 1 .

从球粒陨石标准化稀土元素分配图可以看出, 3 个玄武岩(辉绿岩)明显呈现轻稀土亏损分布(图 6(a)), $(\mathrm{La} / \mathrm{Sm})_{\mathrm{N}}=0.58 \sim 0.76,(\mathrm{La} / \mathrm{Yb})_{\mathrm{N}}=0.59 \sim 0.82$, 与典型的 洋中脊玄武岩相似 ${ }^{[24]}$. 堆晶岩与均质岩系列的Eu元 素正异常主要反映斜长石结晶的结果(图 6(a)). 辉长 岩与苏长质辉长岩的重稀土含量较高, 可能与单斜 


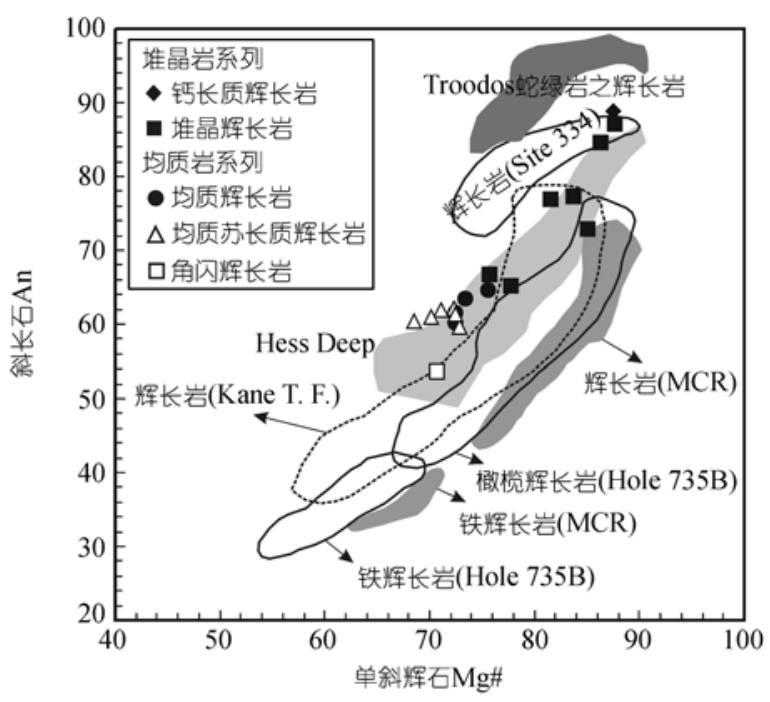

图 5 单斜辉石的 $\mathrm{Mg} \#$ 对斜长石 An 值图 东草河蛇绿岩的成分变化类似于Hess Deep(东太平洋中洋脊)的成分. Site 334, Hole 735B, MCR (Mid-Cayman Rise), Hess Deep, Kane T. F.

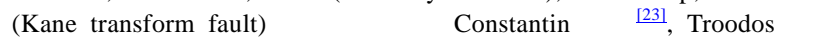
岩的数据来源参考Thy等人 $[22]$
辉石与斜方辉石晶出有关 (单斜辉石与斜方辉石的重

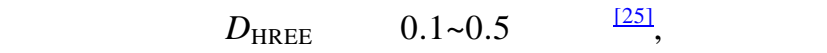
橄榄石与斜长石 10 倍以上). 由N-MORB标准化的微 量元素分布图来看, 3 个玄武岩(辉绿岩)明显呈现平 坦分布, 稍高的 $T h$ 与 $S r$ 元素可能与海水的蚀变作用 有关 ${ }^{[26]}$ (图 6(b)). 经N-MORB标准化的堆晶岩与均质 岩系列的微量元素分布图, 则呈现较大的差异, 但整 体仍是反映结晶分异的特征. Sr和 Eu同时正异常的现 象主要反映斜长石的控制. Nb元素负异常则是因为 堆晶岩与均质岩系列中没有(或缺乏) Nb元素兼容(分 配系数 $\left.D_{\mathrm{Nb}}>1\right)$ 的矿物相.

\section{SHRIMP U-Pb 锆石定年}

选定约 $30 \mathrm{~kg}$ 的新鲜苏长质辉长岩进行锆石分选. 分选出的锆石颗粒长轴约为 $80 \sim 120 \mu \mathrm{m}$, 多数为短柱 状自形晶, 长宽比小于 2, 晶面与晶面界棱线外型清 楚完整, 背散射式影像显示岩浆结晶的振荡环带与 晶面大致平行(图 7(a)). SHRIMP 锆石 U-Pb 定年在北 京离子探针中心完成, 分析条件和过程依标准程序

表 1 东草河蛇绿岩之全岩地球化学成分 ${ }^{a)}$

\begin{tabular}{|c|c|c|c|c|c|c|c|c|}
\hline \multirow{3}{*}{$\begin{array}{l}\text { 岩石系列 } \\
\text { 样本编号 } \\
\text { 岩石种类 }\end{array}$} & \multicolumn{4}{|c|}{ 堆晶岩系列 } & \multirow{3}{*}{$\begin{array}{c}\text { 均质岩系列 } \\
\text { BGS-12A21 } \\
\text { 苏长质辉长岩 }\end{array}$} & \multirow{3}{*}{$\begin{array}{c}\text { 辉绿岩墙 } \\
\text { BGS-12A20 } \\
\text { 辉绿岩 }\end{array}$} & \multicolumn{2}{|c|}{ 玄武质熔岩 } \\
\hline & BGS-11A3 & BGS-10C7 & BGS-11A2 & BGS-12A13 & & & BG-03A & BG-04E \\
\hline & 橄长岩 & 橄长岩 & 钲长质辉长岩 & 辉长岩 & & & 玄武岩 & 玄武岩 \\
\hline \multicolumn{9}{|c|}{ 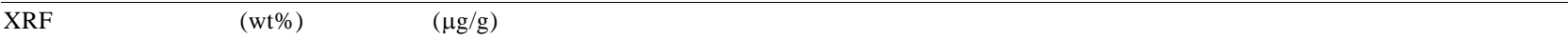 } \\
\hline $\mathrm{SiO}_{2}$ & 41.66 & 43.84 & 44.43 & 49.46 & 51.55 & 49.81 & 50.99 & 51.04 \\
\hline $\mathrm{TiO}_{2}$ & 0.018 & 0.042 & 0.041 & 0.19 & 0.51 & 1.22 & 1.35 & 1.32 \\
\hline $\mathrm{Al}_{2} \mathrm{O}_{3}$ & 5.51 & 15.73 & 26.25 & 19.08 & 15.72 & 15.12 & 14.26 & 14.27 \\
\hline $\mathrm{FeO}_{\text {tot }}$ & 8.99 & 6.21 & 3.36 & 4.18 & 8.31 & 10.59 & 11.16 & 11.74 \\
\hline $\mathrm{MnO}$ & 0.129 & 0.096 & 0.055 & 0.10 & 0.18 & 0.18 & 0.28 & 0.20 \\
\hline $\mathrm{MgO}$ & 40.94 & 25.58 & 10.17 & 9.69 & 8.95 & 7.05 & 7.38 & 7.56 \\
\hline $\mathrm{CaO}$ & 0.72 & 8.33 & 14.45 & 13.66 & 12.45 & 10.99 & 9.06 & 10.43 \\
\hline $\mathrm{Na}_{2} \mathrm{O}$ & 0.05 & 0.03 & 1.25 & 2.26 & 2.34 & 2.97 & 3.25 & 2.87 \\
\hline $\mathrm{K}_{2} \mathrm{O}$ & 0.00 & 0.00 & 0.07 & 0.46 & 0.04 & 0.51 & 0.46 & 0.43 \\
\hline $\mathrm{P}_{2} \mathrm{O}_{5}$ & 0.008 & 0.009 & 0.009 & 0.005 & 0.004 & 0.096 & 0.117 & 0.110 \\
\hline 总量 & 98.03 & 99.87 & 100.07 & 99.08 & 100.06 & 98.54 & 98.31 & 99.97 \\
\hline LOI & 12.40 & 8.49 & 6.32 & 2.90 & 0.52 & 2.15 & 2.17 & 1.68 \\
\hline mg-no. & 90.4 & 89.5 & 86.3 & 82.8 & 69.0 & 57.9 & 57.8 & 57.1 \\
\hline $\mathrm{FeO}$ & 7.75 & 5.35 & 2.89 & 3.60 & 7.17 & 9.13 & 9.62 & 10.13 \\
\hline $\mathrm{Fe}_{2} \mathrm{O}_{3}$ & 1.36 & 0.94 & 0.50 & 0.63 & 1.26 & 1.60 & 1.69 & 1.78 \\
\hline $\mathrm{Ni}$ & 2378 & 1073 & 463 & 169 & 72 & 63 & 52 & 53 \\
\hline $\mathrm{Cr}$ & 5154 & 1555 & 248 & 993 & 244 & 172 & 101 & 112 \\
\hline $\mathrm{V}$ & 36 & 25 & 23 & 119 & 224 & 282 & 312 & 317 \\
\hline $\mathrm{Ga}$ & 2 & 5 & 12 & 13 & 14 & 16 & 17 & 16 \\
\hline $\mathrm{Zn}$ & 51 & 40 & 24 & 23 & 50 & 57 & 203 & 66 \\
\hline $\mathrm{Cu}$ & 19 & 263 & 96 & 131 & 34 & 30 & 74 & 82 \\
\hline \multicolumn{9}{|c|}{ ICP-MS 分析之微量元素 $(\mu \mathrm{g} / \mathrm{g})$} \\
\hline $\mathrm{Ba}$ & 0.32 & 1.94 & 3.58 & 40.57 & 8.38 & 51.49 & 69.46 & 64.00 \\
\hline $\mathrm{Rb}$ & 0.14 & 0.10 & 0.88 & 11.41 & 0.13 & 5.39 & 4.59 & 5.00 \\
\hline
\end{tabular}




\begin{tabular}{|c|c|c|c|c|c|c|c|c|}
\hline 岩石系列 & \multicolumn{4}{|c|}{ 堆晶岩系列 } & \multirow{3}{*}{$\begin{array}{c}\text { 均质岩系列 } \\
\text { BGS-12A21 } \\
\text { 苏长质辉长岩 }\end{array}$} & \multirow{3}{*}{$\begin{array}{c}\text { 辉绿岩墙 } \\
\text { BGS-12A20 } \\
\text { 辉绿岩 }\end{array}$} & \multicolumn{2}{|c|}{ 玄武质熔岩 } \\
\hline 样本编号 & BGS-11A3 & BGS-10C7 & BGS-11A2 & BGS-12A13 & & & BG-03A & BG-04E \\
\hline 岩石种类 & 橄长岩 & 橄长岩 & 钲长质辉长岩 & 辉长岩 & & & 玄武岩 & 玄武岩 \\
\hline $\mathrm{Sr}$ & 0.58 & 4.96 & 110.6 & 209 & 97 & 162 & 161 & 174 \\
\hline $\mathrm{Zr}$ & 0.61 & 0.90 & 1.04 & 3.81 & 2.74 & 56.76 & 64.35 & 68.00 \\
\hline $\mathrm{Y}$ & 0.38 & 0.81 & 1.08 & 5.84 & 9.00 & 29.20 & 29.30 & 31.92 \\
\hline $\mathrm{Nb}$ & 0.010 & 0.009 & 0.010 & 0.08 & 0.05 & 1.65 & 2.82 & 2.44 \\
\hline Cs & 0.02 & 0.61 & 0.29 & 4.45 & 0.06 & 0.44 & 0.47 & 0.78 \\
\hline Sc & 5.45 & 4.78 & 5.48 & 39.1 & 47.2 & 43.2 & 42.1 & 49.1 \\
\hline $\mathrm{Hf}$ & 0.020 & 0.035 & 0.035 & 0.16 & 0.17 & 1.74 & 1.98 & 2.03 \\
\hline Ta & 0.002 & 0.002 & 0.002 & 0.008 & 0.006 & 0.118 & 0.210 & - \\
\hline $\mathrm{Pb}$ & 0.63 & 0.75 & 0.20 & 0.27 & 0.29 & 0.26 & 0.37 & 1.48 \\
\hline Th & 0.015 & 0.013 & 0.013 & 0.072 & 0.053 & 0.237 & 0.303 & 0.180 \\
\hline $\mathrm{U}$ & 0.005 & 0.006 & 0.005 & 0.012 & 0.010 & 0.059 & 0.070 & 0.050 \\
\hline $\mathrm{La}$ & 0.035 & 0.051 & 0.080 & 0.23 & 0.19 & 2.38 & 3.33 & 3.00 \\
\hline $\mathrm{Ce}$ & 0.078 & 0.160 & 0.204 & 0.78 & 0.68 & 6.73 & 8.82 & 8.52 \\
\hline $\operatorname{Pr}$ & 0.011 & 0.027 & 0.039 & 0.14 & 0.13 & 1.10 & 1.34 & 1.37 \\
\hline $\mathrm{Nd}$ & 0.049 & 0.144 & 0.188 & 0.83 & 0.93 & 6.37 & 7.37 & 7.57 \\
\hline $\mathrm{Sm}$ & 0.019 & 0.053 & 0.080 & 0.42 & 0.57 & 2.64 & 2.82 & 2.97 \\
\hline $\mathrm{Eu}$ & 0.014 & 0.067 & 0.122 & 0.29 & 0.48 & 0.97 & 1.00 & 1.12 \\
\hline Gd & 0.030 & 0.112 & 0.133 & 0.70 & 1.03 & 3.76 & 3.93 & 4.20 \\
\hline $\mathrm{Tb}$ & 0.007 & 0.020 & 0.027 & 0.15 & 0.21 & 0.74 & 0.75 & 0.81 \\
\hline Dy & 0.051 & 0.127 & 0.194 & 1.04 & 1.55 & 5.10 & 5.18 & 5.60 \\
\hline Ho & 0.013 & 0.029 & 0.043 & 0.22 & 0.36 & 1.10 & 1.15 & 1.21 \\
\hline Er & 0.048 & 0.083 & 0.118 & 0.62 & 1.00 & 3.15 & 3.22 & 3.40 \\
\hline $\mathrm{Tm}$ & 0.008 & 0.014 & 0.017 & 0.09 & 0.15 & 0.46 & 0.47 & 0.50 \\
\hline $\mathrm{Yb}$ & 0.051 & 0.098 & 0.104 & 0.54 & 0.93 & 2.87 & 2.90 & 3.18 \\
\hline $\mathrm{Lu}$ & 0.010 & 0.017 & 0.017 & 0.09 & 0.15 & 0.45 & 0.46 & 0.50 \\
\hline
\end{tabular}

a) LOI: 烧失量; $\mathrm{Fe}_{2} \mathrm{O}_{3}$ 占全部 $\mathrm{Fe}$ 的 $0.15, \mathrm{FeO}$ 占全部 $\mathrm{Fe}$ 的 $0.85 ; m g-n o=100 \mathrm{Mg} /\left(\mathrm{Mg}^{2} \mathrm{Fe}^{2+}\right)$; : 未测

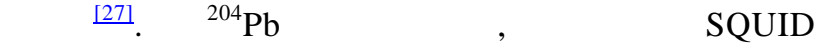
和Isoplot程序 $[28]$, 加权平均年龄计算误差为 $2 \sigma$.

共在 17 粒锆石中测定 17 个数据点, 它们的 $\mathrm{Th} / \mathrm{U}$ 比值为 $0.64 \sim 0.99$, 具有典型岩浆结晶锆石的特征 $[29]$, 其 ${ }^{206} \mathrm{~Pb} /{ }^{238} \mathrm{U}$ 表面年龄的加权平均值为 $(497 \pm 7) \mathrm{Ma}$ $(M S W D=2.6)($ 见表 2 与图 7(b)).

由于亏损地幔处于Zr不饱和状态, 所以起源于 洋壳的原始蛇绿岩和辉长岩不可能结晶出可供 $\mathrm{U}-\mathrm{Pb}$ 定年用的锆石 ${ }^{[30]}$. 显然, 苏长质辉长岩中锆石 U-Pb 年龄测定, 无法代表软流圈地幔熔融产生原始岩浆 后的橄榄岩-辉长岩结晶事件. 因此, 如果在蛇绿岩 组合的橄榄岩-辉长岩中发现岩浆成因锆石, 可能说 明在蛇绿岩构造侵位过程中或者发生部分熔融直接 结晶出锆石, 或者受到地壳混染后发生部分熔融结 晶出锆石, 或者是残留的壳源锆石 30$]$. 北祁连造山 带的邻近地区皆为元古代陆壳 [31 33] , 早奥陶世锆石 $\mathrm{U}-\mathrm{Pb}$ 年龄显然不是残留的壳源锆石. 所以, 存在于东 草河蛇绿岩中苏长质辉长岩的锆石年龄可能纪录了 蛇绿岩构造侵位过程中出现的部分熔融事件时代.
因此, 可以推断的古祁连洋应该存在于晚寒武-中寒 武世或更早, 而不是早奥陶世.

\section{6 地质意义}

东草河蛇绿岩的岩石组合、矿物结晶顺序、矿物 化学特性、元素地球化学与 $N d-S r$ 同位素特征(另文发 表)都反映出洋中脊(N-MOR)环境的特征, 表明其形 成于洋中脊或成熟的弧后盆地环境. 从岩石建造来 看, 东草河蛇绿岩是一个保存完整的洋壳残块. 早古 生代保存完整的单一洋壳残片并不多见, Newfoundland的Annieopsquotch蛇绿岩(约 $480 \mathrm{Ma}$ )是其中一个, 但它相对缺失橄榄堆晶岩的部分 [34]. 东草河蛇绿岩 则是保存相对较完整的一个实例.

多数的研究认为, 古祁连洋在奥陶纪时向北俯 冲 $[3,6,7,10]$. 在北祁连造山带中段的构造分带上, 由南 向北分别为: 托莱山蛇绿岩带、走廊南山俯冲杂岩带、 走廊南山主岛弧带与走廊南山北坡的弧后盆地 ${ }^{[3]}$. 张 建新等人 锆石年代为 466 481 Ma, 而宋述光等人 [36]利用锆石 

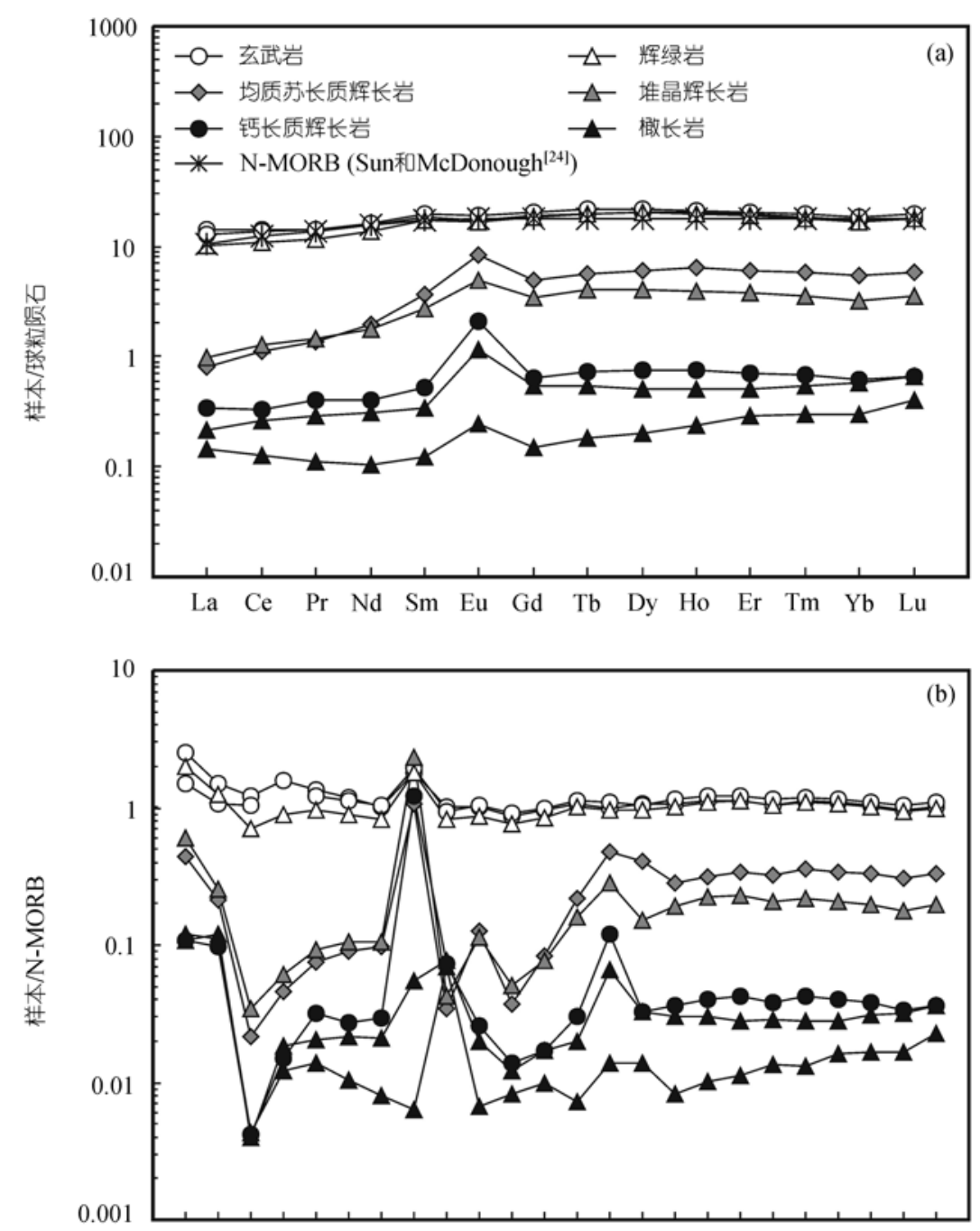

Th U NbTa La Ce Pr Sr PNd Zr Hf SmEu Ti Gd TbDy Y HoEr TmYb Lu

图 6

(a) 球粒陨石标准化稀土元素分配图; (b) N-MORB标准化的微量元素分布图. 标准化数据来源Sun和McDonough ${ }^{[24]}$

SHRIMP法测定了俯冲杂岩带高压变质榴辉岩年代 为 $463 \sim 468 \mathrm{Ma}$. 上述的年龄数据反映了古祁连洋发 生俯冲与其俯冲引发的岛弧火山活动主要在中奥陶 世 ${ }^{[36]}$. 东草河蛇绿岩属于托莱山蛇绿岩带的一部分, 属古祁连洋的残留部分, 而锆石年代学研究显示它 构造侵位时代为早奥陶世, 从古板块构造运动的时 序来看, 代表古祁连洋至少在早奥陶纪(约 $497 \mathrm{Ma}$ )前 就向北俯冲, 比岛弧岩浆活动及俯冲杂岩带高压榴 辉岩变质作用的年代更早. 所以, 东草河蛇绿岩是古 祁连洋向北俯冲的一个重要时间制约.

当然, 也有部分的研究者认为古祁连洋向南俯 冲 ${ }^{[37]}$ 或者是双向俯冲 ${ }^{[4]}$. 因此, 张旗等人 ${ }^{[4]}$ 认为北祁 连山的蛇绿岩属科迪勒拉型. 也就是说, 北祁连蛇绿
岩都是岛弧或小洋盆环境. 这些小洋盆的形成与演 化都与一个大洋盆的活动有关 ${ }^{[4]}$. 已有的研究认为 托莱山蛇绿岩带中的玉石沟蛇绿岩的形成时代(或构 造侵位年代)约为 $550 \mathrm{Ma}^{[38]}$. 假如玉石沟蛇绿岩和东 草河蛇绿岩(构造侵位年代约 $497 \mathrm{Ma}$ )形成于同一小 洋盆或成熟的弧后盆地环境, 两者的年代学差异则 暗示这些小洋盆或弧后盆地至少存在 $50 \mathrm{Ma}$ 以上, 而 与之相关的大洋盆存在时间应更长.

最近的研究显示 ${ }^{[39,40]}$, 北祁连山的九个泉、大岔 大阪、老虎山与玉石沟蛇绿岩都具有印度洋MORB型 的同位素组成特征，表明古祁连洋可能曾是特提斯构 造域的一部分. 侯青叶等人 [39]指出, 对于已知的特提 斯构造域的蛇绿岩, 其MORB型玄武岩的微量元 


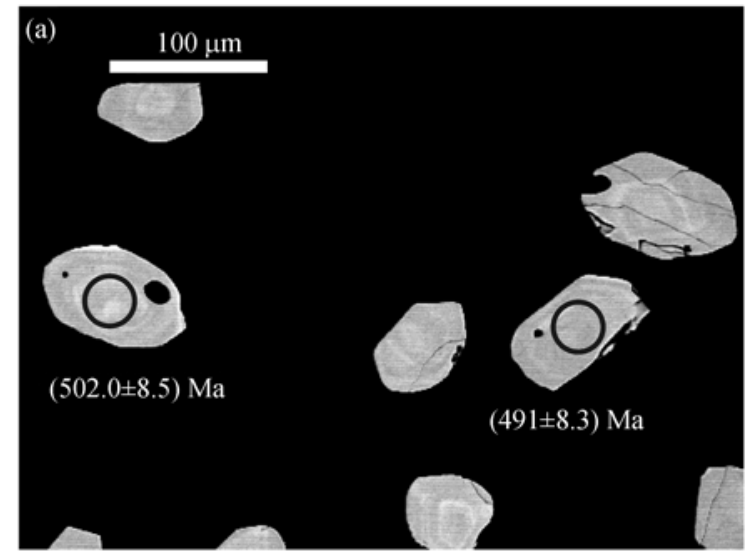

图 7

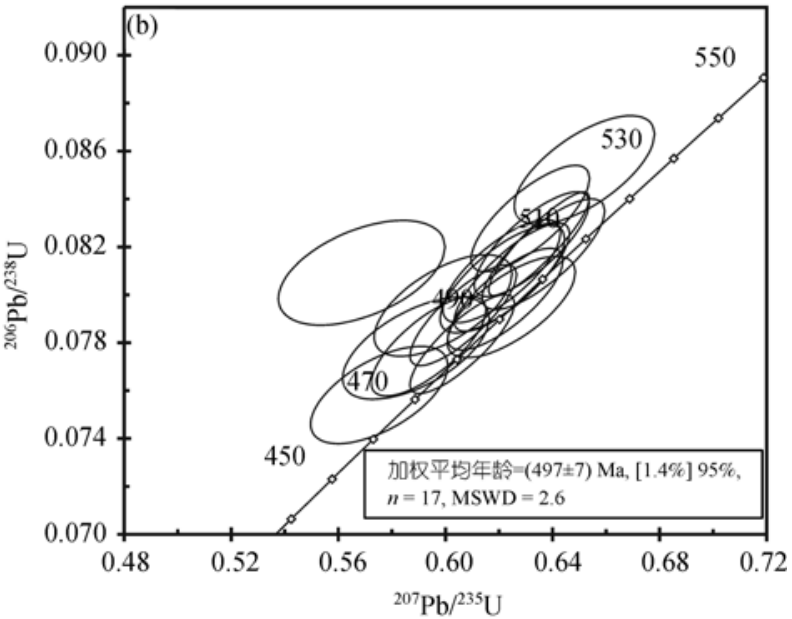

(a) 苏长质辉长岩之锆石的背散射式影像; (b) 东草河蛇绿岩苏长质辉长岩之锆石 U-Pb 谐和年龄图

表 2 东草河蛇绿岩之苏长质辉长岩中的锆石 SHRIMP 定年资料

\begin{tabular}{|c|c|c|c|c|c|c|c|c|c|c|c|c|}
\hline \multirow{2}{*}{ 测点 } & \multirow{2}{*}{${ }^{206} \mathrm{~Pb}_{\mathrm{c}} / \%$} & \multicolumn{3}{|c|}{ 浓度/ $\mu \mathrm{g} \cdot \mathrm{g}^{-1}$} & \multirow{2}{*}{${ }^{232} \mathrm{Th}^{/ 238} \mathrm{U}$} & \multirow{2}{*}{$\begin{array}{c}{ }^{206} \mathrm{~Pb} /{ }^{238} \mathrm{U} \\
\text { 年龄/Ma }\end{array}$} & \multicolumn{6}{|c|}{ 放射性同位素比值 } \\
\hline & & $\mathrm{U}$ & Th & ${ }^{206} \mathrm{~Pb}^{*}$ & & & ${ }^{207} \mathrm{~Pb}^{*} /{ }^{206} \mathrm{~Pb}^{*}$ & $\pm \%$ & ${ }^{207} \mathrm{~Pb}^{*} /{ }^{235} \mathrm{U}$ & $\pm \%$ & ${ }^{206} \mathrm{~Pb}^{*} /{ }^{238} \mathrm{U}$ & $\pm \%$ \\
\hline BGS-1 & 0.13 & 391 & 288 & 26.2 & 0.76 & $483.3 \pm 8.2$ & 0.05531 & 1.6 & 0.594 & 2.4 & 0.0778 & 1.8 \\
\hline BGS-2 & 0.03 & 290 & 253 & 20.1 & 0.90 & $500.5 \pm 8.9$ & 0.05613 & 1.3 & 0.625 & 2.3 & 0.0807 & 1.8 \\
\hline BGS-3 & 0.31 & 373 & 296 & 26.1 & 0.82 & $501.5 \pm 8.6$ & 0.0510 & 3.1 & 0.570 & 3.6 & 0.0809 & 1.8 \\
\hline BGS-4 & 0.52 & 429 & 359 & 30.3 & 0.87 & $508.7 \pm 8.6$ & 0.05585 & 1.4 & 0.632 & 2.2 & 0.0821 & 1.8 \\
\hline BGS-5 & 0.04 & 412 & 256 & 29.5 & 0.64 & $515.1 \pm 8.7$ & 0.05508 & 1.5 & 0.632 & 2.3 & 0.0832 & 1.8 \\
\hline BGS-6 & 0.12 & 395 & 380 & 27.1 & 0.99 & $495.0 \pm 8.4$ & 0.05656 & 1.5 & 0.623 & 2.3 & 0.0798 & 1.8 \\
\hline BGS-7 & 0.70 & 527 & 483 & 38.6 & 0.95 & $527.1 \pm 8.9$ & 0.0555 & 2.0 & 0.652 & 2.6 & 0.0852 & 1.8 \\
\hline BGS-8 & 0.64 & 352 & 282 & 23.0 & 0.83 & $471.1 \pm 8.0$ & 0.0550 & 2.4 & 0.576 & 2.9 & 0.0758 & 1.8 \\
\hline BGS-9 & 0.28 & 312 & 241 & 21.6 & 0.80 & $500.1 \pm 8.9$ & 0.05586 & 1.6 & 0.622 & 2.5 & 0.0807 & 1.8 \\
\hline BGS-10 & 0.44 & 494 & 398 & 34.7 & 0.83 & $506.2 \pm 9.1$ & 0.05652 & 1.5 & 0.637 & 2.4 & 0.0817 & 1.9 \\
\hline BGS-11 & 0.74 & 418 & 336 & 28.7 & 0.83 & $493.0 \pm 8.3$ & 0.0570 & 1.8 & 0.626 & 2.5 & 0.0795 & 1.8 \\
\hline BGS-12 & 0.02 & 478 & 350 & 32.0 & 0.76 & $483.8 \pm 8.2$ & 0.05641 & 1.2 & 0.606 & 2.1 & 0.0779 & 1.7 \\
\hline BGS-13 & 0.52 & 420 & 403 & 29.3 & 0.99 & $502.0 \pm 8.5$ & 0.05561 & 1.5 & 0.621 & 2.3 & 0.0810 & 1.8 \\
\hline BGS-14 & 0.26 & 396 & 340 & 27.0 & 0.89 & $491.0 \pm 8.3$ & 0.05559 & 1.3 & 0.607 & 2.2 & 0.0791 & 1.8 \\
\hline BGS-15 & 0.08 & 180 & 116 & 12.0 & 0.67 & $482.8 \pm 8.4$ & 0.0549 & 2.5 & 0.589 & 3.1 & 0.0778 & 1.8 \\
\hline BGS-16 & 0.21 & 573 & 497 & 40.5 & 0.90 & $508.8 \pm 8.5$ & 0.05608 & 0.90 & 0.635 & 2.0 & 0.0821 & 1.7 \\
\hline BGS-17 & 0.68 & 403 & 292 & 27.7 & 0.75 & $493.4 \pm 8.4$ & 0.0546 & 2.2 & 0.600 & 2.8 & 0.0795 & 1.8 \\
\hline
\end{tabular}

素比值大致在一定的范围内变化. 东草河蛇绿岩的 玄武质岩石微量元素比值特征为: $\mathrm{Zr} / \mathrm{Nb}(22.8 \sim 34.4)$, $\mathrm{La} / \mathrm{Nb}$ (1.2 1.4), $\mathrm{Ti} / \mathrm{Zr}$ (116 129), Ti/V (25.0 26.0), $\mathrm{TiO}_{2} /{ }_{2} \mathrm{O}_{5} \quad(11.5 \sim 12.7), \quad \mathrm{Th} / \mathrm{La} \quad(0.06 \sim 0.10), \quad \mathrm{Rb} / \mathrm{Sr}$ (0.028 0.033), 与特提斯构造域的蛇绿岩是一致的, 这暗示着东草河蛇绿岩也是原特提斯洋盆的一部分.

致谢 SHRIMP 定年工作得到了万渝生和陶华的帮助. 成 文期间，得到了张建新与孟繁㙂的帮助，两位评审专家提 出的建设性修改意见，在此一并致谢://engine.scichina.com/doi/15.

\section{参考文献}

1 Coleman R G. Ophiolites, Ancient Oceanic Lithosphere? New York: Springer, 1977

2 张旗, 周国庆. 中国蛇绿岩. 北京: 科学出版社, 2001

3 许志琴, 徐惠芬, 张建新, 等. 北祁连走廊南山加里东俯冲杂岩 增生地体及其动力学. 地质学报, 1994, 68(1): 1-15

4 张旗, 孙晓猛, 周德进. 北祁连蛇绿岩的特征、形成环境及其构 造意义. 地球科学进展, 1997, 12: 366-393

1 Yang $\mathrm{H}, \mathrm{Y}, \mathrm{Wu}$ Y M M , WuC. Petrology of an arc-oceanic crust con- 
tact zone in the Laohushan back-arc basin, the eastern section of the North Qilian Mounatins, NW China. Acta Geol Sin-Engl Ed, 2002, 76: $1-13$

6 Xia L Q, Xia Z H, Xu X Y. Magmagenesis in the Ordovician backarc basins of the Northern Qilian Mountains, China. Geol Soc Am Bull, 2003, 115: 1510 -1522[DOI]

7 Wang C Y, Zhang Q, Qian Q, et al. Geochemistry of the early Paleozoic Baiyin volcanic rocks (NW China): Implications for the tectonic evolution of the North Qilian orogenic belt. J Geol, 2005, 113: 83-94[DOI]

8 Wu H Q, Feng Y M, Song, S G. Metamorphism and deformation of blueschist belts and their tectonic implications, North Qilian Mountains, China. J Metamorph Geol, 1993, 11: 523-536[DOI]

9 宋述光. 北祁连俯冲杂岩代的构造意义. 地球科学进展, 1997, 12(4): 351-365

10 Song S G, Zhang L F, Niu Y L, et al. Evolution from oceanic subduction to continental collision: A case study from the northern Tibetan Plateau based on geochemical and geochronological data. J Petrol, 2006, 47: 435-455[DOI]

11 McCollom T M, Shock E L. Fluid-rock interactions in the lower oceanic crust: Thermodynamic models of hydrothermal alteration. J Geophys Res, 1998, 103: 547—575[DOI]

12 Bloomer S H, Meyer P S, Dick H J B, et al. Textural and mineralogical variations in gabbroic rocks from Hole 735B. In: von Herzen R P, Robinson P T, eds. Proceedings of the Ocean Drilling Program, Scientific Results 118. College Station, Texas, Ocean Drilling Program, 1991. 21-39

13 Barnes S J, Roeder P L. The range of spinel compositions in terrestrial mafic and ultramafic rocks. J Petrol, 2001, 42: 22792302[DOI]

14 Elthon D. Petrology of gabbroic rocks from the Mid-Cayman rise spreading center. J Geophys Res, 1987, 92: 658—682

15 Arai S, Matsukage K. Petrology of a chromitite micropod from Hess Deep, equatorial Pacific: A comparison between abyssal and alpine-type podifrom chromitites. Lithos, 1998, 43: 1-14[DOI]

16 Arai S, Uesugi J, Ahmed A H. Upper crustal podiform chromitite from the northern Oman ophiolite as the stratigraphically shallowest chromitite in ophiolite and its implication for $\mathrm{Cr}$ concentration. Contrib Mineral Petrol, 2004, 147: 145-154[DOI]

17 Elthon D, Stewart M, Ross D K. Compositional trends of minerals in oceanic cumulates. J Geophys Res, 1992, 97: 15189-15199

18 Arai S, Matsukage K. Petrology of the gabbro-troctolite-peridotite complex from Hess Deep, equatorial Pacific: Implications for mantle-melt interaction within the oceanic lithosphere. In: Mével C, Gillis K M, Allan J F, et al, eds. Proceeding of the Ocean Drilling Program, Scientific Results147. College Station, Texas, Ocean Drilling Program. 1996. 135-155

19 Arai S, Matsukage K, Isobe E, et al. Concentration of incompatible elements in oceanic mantle: Effect of melt/wall interaction in stagnant or failed melt conduits within/peridotite. Geochim Cos- mochim Acta, 1997, 61: 671—675[DOI]

20 Ross K, Elthon D. Cumulus and postcumulus crystallization in the oceanic crust: Major- and trace-element geochemistry of LEG 153 gabbroic rocks. In: Karson J A, Cannat M, Miller D J, et al, eds. Proceeding of the Ocean Drilling Program, Scientific Results 153. College Station, Texas, Ocean Drilling Program, 1997. 333-350

21 Takagi D, Sato H, Nakagawa M. Experimental study of a low-alkali tholeiite at 1 5 kbar: Optimal condition for the crystallization of high-An plagioclase in hydrous arc tholeiite. Contrib Mineral Petrol, 2005, 149: 527-540[DOI]

22 Thy P, Schiffman P, Moores E M. Igneous mineral stratigraphy and Chemistry of the Cyprus crustal study project drill core in the Plutonic sequences of the Troodos Ophiolite. In: Gibson I L, Malpas J, Robinson P T, et al, eds. Cyprus Crustal Study Project: Initial Report. Hole CY-4, 1989. 147-185

23 Constantin M, Hékinian R, Bideau D, et al. Construction of the oceanic lithosphere by magmatic intrusions: Petrological evidence from plutonic rocks formed along the fast-spreading East Pacific Rise. Geology, 1996, 24(8): 731-734

24 Sun S S, McDonough W F. Chemical and isotopic systematics of oceanic basalts: Implications for mantle composition and processes. In: Saunders A D, Norry M J, eds. Magmatism in the Ocean Basins. Geological Society, London, Special Publication 42. Oxford: Blackwell, 1989. 313-346

25 Bédard J H. A procedure for calculating the equilibrium distribution of trace elements among the minerals of cumulate rocks, and the concentration of trace elements in the coexisting liquids. Chem Geol, 1994, 118: 143-153[DOI]

26 Valsami-Jones E, Ragnarsdöttir K V. Controls on uranium and thorium behavior in ocean-floor hydrothermal systems: Examples from the Pindos ophiolite, Greece. Chem Geol, 1997, 135: $263-$ 274[DOI]

27 Willians I S. U-Th-Pb geochronology by ion microprobe. Rev Econ Geol, 1998, 7: 1-35

28 Ludwig K R. Isoplot/Ex version 2.4. A Geochronological Toolkit for Microsoft Excel. Berkeley Geochron Centre Spec Publ, 2000. $1-56$

29 Hoskin P W O, Schaltegger U. The composition of zircon and igneous and metamorphic petrogenesis. In: Hanchar J M, Hoskin $\mathrm{P}$ W O, eds. Zircon: Reviews in Mineralogy and Geochemistry 53. Mineralogical Society of America, 2003. 27-62

30 Zheng Y F, Zhao Z F, Wu Y B, et al. Zircon U-Pb age, Hf and O isotope constraints on protolith origin of ultrahigh-pressure eclogite and gneiss in the Dabie orogen. Chem Geol, 2006, 231: 135-158[DOI]

31 Wan Y S, Xu Z Q, Yang J S, et al. Ages and compositions of the Precambrian high-grade basement of the Qilian terrane and adjacent areas. Acta Geol Sin-Engl Ed, 2001, 75(4): 375-384

32 曾建元, 杨宏仪, 万渝生, 等. 北祁连山变质杂岩中新元古代 ( 775 Ma)岩浆活动纪录的发现: 来自 SHRIMP 锆石 U-Pb 定年 的证据. 科学通报, $2006,51(5)$ : 575-581 
33 董国安, 杨宏仪, 刘敦一, 等. 龙首山岩群碎屑锆石 SHRIMP $\mathrm{U}-\mathrm{Pb}$ 年代学及其地质意义. 科学通报, 2007, 52(6): 688-697

34 Lissenberg C J, Bédard J H, van Staal C R. The structure and geochemistry of the gabbro zone of the Annieopsquotch ophiolite, Newfoundland: Implications for lower crustal accretion at spreading ridges. Earth Planet Sci Lett, 2004, 229: 105-123[DOI]

35 张建新, 许志琴, 徐惠芬, 等. 北祁连中段俯冲杂岩、火山弧的 时代探讨. 岩石矿物学杂志, 1997, 16: 112-119

36 宋述光, 张立飞, Niu Y L, 等. 北祁连山榴辉岩锆石 SHRIMP 定 年及其构造意义. 科学通报, 2004, 49(6): 592-595
37 Gehrels G E, Yin A, Wang X F. Magmatic history of the northeastern Tibetan Plateau. J Geophys Res, 2003, 108(B9), 2423, doi: 10.1029/2002JB001876[DOI]

38 史仁灯, 杨经绥, 吴才来, 等. 北祁连玉石沟蛇绿岩形成于晚震 旦世的 SHRIMP 年龄证据. 地质学报, 2004, 78(5): 649-657

39 侯青叶, 赵志丹, 张宏飞, 等. 北祁连玉石沟蛇绿岩印度洋 MORB 型同位素组成特征及其地质意义. 中国科学 D 辑: 地球 科学, 2005, 35(8): 710-719

40 侯青叶, 赵志丹, 张本仁, 等. 青藏高原东北缘特提斯构造域界 线的探讨. 岩石学报, 2006, 22(3): 567-577 
附录 1 东草河蛇绿岩的代表性铬尖晶石电子探针成分 ${ }^{a)}$

\begin{tabular}{|c|c|c|c|c|c|c|c|c|c|c|c|c|}
\hline 样本号 & 矿物相 & $\mathrm{Al}_{2} \mathrm{O}_{3}$ & $\mathrm{TiO}_{2}$ & $\mathrm{Cr}_{2} \mathrm{O}_{3}$ & $\mathrm{FeO}$ & $\mathrm{Fe}_{2} \mathrm{O}_{3}$ & $\mathrm{MnO}$ & $\mathrm{MgO}$ & 总量 & Mg\# & Cr\# & $\mathrm{Fe}^{3+} \#$ \\
\hline \multicolumn{13}{|c|}{ 堆晶纯橄岩-橄长岩 } \\
\hline 10B1 & Spl & 28.73 & 0.19 & 37.40 & 14.37 & 4.57 & - & 14.56 & 99.82 & 64.4 & 46.6 & 5.1 \\
\hline $11 \mathrm{~A} 3$ & Spl & 26.62 & 0.39 & 38.94 & 16.76 & 4.69 & - & 13.02 & 100.42 & 58.1 & 49.5 & 5.4 \\
\hline 11A3-2 & Spl & 21.7 & 0.24 & 40.28 & 20.06 & 7.70 & 0.41 & 9.96 & 100.35 & 47.0 & 55.5 & 9.2 \\
\hline 11A7 & Spl & 25.78 & 0.22 & 39.59 & 19.24 & 3.93 & - & 11.11 & 99.87 & 50.7 & 50.7 & 4.6 \\
\hline \multicolumn{13}{|c|}{ 不谐和的纯橄岩-橄长岩 } \\
\hline 04A & Spl & 18.28 & 1.62 & 41.58 & 19.84 & 7.70 & - & 10.70 & 99.72 & 49.0 & 60.4 & 9.6 \\
\hline \multirow[t]{2}{*}{ 04B } & Spl & 15.81 & 1.87 & 40.24 & 25.62 & 9.96 & 0.44 & 6.70 & 100.64 & 31.8 & 63.1 & 12.9 \\
\hline & Spl* & 35.24 & 0.64 & 27.89 & 13.36 & 6.81 & - & 16.11 & 100.04 & 68.3 & 34.7 & 7.5 \\
\hline $05 \mathrm{~A}$ & Spl & 20.75 & 0.77 & 42.41 & 22.44 & 4.77 & 0.41 & 8.61 & 100.16 & 40.6 & 57.8 & 5.8 \\
\hline $10 \mathrm{C} 3$ & Spl & 27.95 & 0.77 & 33.90 & 16.84 & 6.71 & - & 13.06 & 99.23 & 58.0 & 44.9 & 7.8 \\
\hline 11A5 & Spl & 17.91 & 1.60 & 41.93 & 20.33 & 7.12 & 0.47 & 9.94 & 99.29 & 46.6 & 61.1 & 9.0 \\
\hline \multicolumn{13}{|c|}{ 钲长质辉长岩 } \\
\hline 11A6 & Spl & 24.81 & 0.60 & 38.69 & 20.37 & 5.58 & - & 10.65 & 100.70 & 48.2 & 51.1 & 6.6 \\
\hline
\end{tabular}

a) Spl: 铬尖晶石(Cr-spinel); $\mathrm{Mg} \#: 100 \mathrm{Mg} /\left(\mathrm{Mg}+\mathrm{Fe}^{2+}\right) ; \mathrm{Cr} \#: 100 \mathrm{Cr} /(\mathrm{Cr}+\mathrm{Al}) ; \mathrm{Fe}^{3+} \#: 100 \mathrm{Fe}^{3+} /\left(\mathrm{Fe}^{3+}+\mathrm{Cr}+\mathrm{Al}\right) ; \mathrm{FeO}$ 和 $\mathrm{Fe}_{2} \mathrm{O}_{3}$ 系利用 $\mathrm{AB}_{2} \mathrm{O}_{4}$ 标准配 位数计算. $\mathrm{Spl}^{*}$ : 红棕色铬尖晶石; -: 未测

附录 2 东草河蛇绿岩的代表性辉石电子探针成分 ${ }^{\text {a) }}$

\begin{tabular}{|c|c|c|c|c|c|c|c|c|c|c|c|c|c|c|c|}
\hline 样本号 & 矿物相 & $\mathrm{SiO}_{2}$ & $\mathrm{Al}_{2} \mathrm{O}_{3}$ & $\mathrm{TiO}_{2}$ & $\mathrm{Cr}_{2} \mathrm{O}_{3}$ & $\mathrm{FeO}$ & $\mathrm{MnO}$ & $\mathrm{MgO}$ & $\mathrm{CaO}$ & $\mathrm{Na}_{2} \mathrm{O}$ & 总量 & Mg\# & En & Fs & Wo \\
\hline \multicolumn{16}{|c|}{ 堆晶橄长岩 } \\
\hline $11 \mathrm{~A} 7$ & Cpx & 52.56 & 2.28 & 0.21 & 1.70 & 2.49 & 0.00 & 15.33 & 24.82 & 0.36 & 99.75 & 91.7 & 44.4 & 4.0 & 51.6 \\
\hline \multicolumn{16}{|c|}{ 不谐和的纯橄岩-橄长岩 } \\
\hline $04 \mathrm{~A}$ & Сpx & 50.96 & 3.50 & 1.30 & 1.31 & 2.64 & 0.15 & 15.90 & 23.24 & 0.47 & 99.47 & 91.5 & 46.7 & 4.3 & 49.0 \\
\hline 04B & Cpx & 52.66 & 3.05 & 0.54 & 1.32 & 3.12 & 0.15 & 16.14 & 23.72 & 0.24 & 100.94 & 90.2 & 46.2 & 5.0 & 48.8 \\
\hline 11A5 & Сpx & 51.32 & 3.62 & 0.39 & 1.37 & 3.09 & 0.18 & 16.03 & 23.68 & 0.34 & 100.02 & 90.2 & 46.1 & 5.0 & 48.9 \\
\hline \multicolumn{16}{|c|}{ 䥻长质辉长岩 } \\
\hline $11 \mathrm{~A} 2$ & Cpx & 51.70 & 3.59 & 0.36 & 0.82 & 4.21 & 0.19 & 16.07 & 22.86 & 0.17 & 99.97 & 87.2 & 46.1 & 6.8 & 47.1 \\
\hline \multicolumn{16}{|c|}{ 堆晶辉长岩 } \\
\hline 10B2 & Срх & 53.06 & 2.64 & 0.39 & 0.43 & 5.35 & 0.09 & 16.04 & 22.48 & 0.35 & 100.83 & 84.2 & 45.6 & 8.5 & 45.9 \\
\hline 10B3 & Срx & 53.03 & 3.21 & 0.16 & 0.31 & 4.40 & 0.14 & 17.15 & 22.21 & 0.37 & 100.98 & 87.4 & 48.2 & 6.9 & 44.9 \\
\hline 10B5 & Срx & 52.51 & 3.27 & 0.35 & 0.60 & 4.80 & 0.12 & 15.40 & 23.41 & 0.21 & 100.67 & 85.1 & 44.1 & 7.7 & 48.2 \\
\hline 10B7 & Срх & 51.81 & 2.69 & 0.54 & 0.27 & 7.13 & 0.20 & 14.45 & 22.83 & 0.29 & 100.21 & 78.3 & 41.5 & 11.5 & 47.1 \\
\hline 10B13 & Сpx & 51.85 & 3.04 & 0.23 & 0.82 & 4.48 & 0.00 & 16.40 & 22.79 & 0.30 & 99.91 & 86.7 & 46.5 & 7.1 & 46.4 \\
\hline 12A12 & Сpx & 51.60 & 2.66 & 0.87 & 0.26 & 7.35 & 0.26 & 13.72 & 23.44 & 0.37 & 100.53 & 76.9 & 39.6 & 11.9 & 48.6 \\
\hline $12 \mathrm{~A} 13$ & Сpx & 52.12 & 2.62 & 0.51 & 0.52 & 6.31 & 0.18 & 15.43 & 22.43 & 0.20 & 100.32 & 81.3 & 44.0 & 10.1 & 45.9 \\
\hline \multicolumn{16}{|c|}{ 具嵌晶结构之堆晶辉长岩 } \\
\hline \multirow[t]{2}{*}{ 10B6 } & $\mathrm{Cpx}^{\mathrm{c}}$ & 52.83 & 2.09 & 0.26 & 0.34 & 5.33 & 0.17 & 16.74 & 21.60 & 0.48 & 99.84 & 84.8 & 47.5 & 8.5 & 44.0 \\
\hline & $\mathrm{Cpx}^{\mathrm{r}}$ & 48.79 & 4.47 & 0.96 & 0.04 & 10.29 & 0.32 & 14.62 & 19.84 & 0.39 & 99.72 & 71.7 & 42.2 & 16.7 & 41.2 \\
\hline \multicolumn{16}{|c|}{ 均质辉长岩 } \\
\hline $04 \mathrm{M}$ & Сpx & 51.43 & 2.96 & 0.64 & 0.25 & 7.95 & 0.20 & 13.96 & 22.19 & 0.37 & 99.95 & 75.8 & 40.6 & 13.0 & 46.4 \\
\hline $12 \mathrm{~A} 6$ & Сpx & 51.37 & 2.47 & 0.90 & 0.21 & 9.34 & 0.31 & 13.79 & 21.68 & 0.41 & 100.48 & 72.5 & 39.8 & 15.1 & 45.0 \\
\hline $12 \mathrm{~A} 10$ & Сpx & 52.18 & 2.46 & 0.73 & 0.05 & 9.39 & 0.23 & 13.50 & 21.85 & 0.46 & 100.85 & 71.9 & 39.2 & 15.3 & 45.6 \\
\hline 12A14 & Срx & 51.12 & 2.44 & 0.88 & 0.20 & 9.42 & 0.13 & 13.78 & 22.03 & 0.34 & 100.34 & 72.3 & 39.5 & 15.1 & 45.4 \\
\hline \multicolumn{16}{|c|}{ 均质苏长质辉长岩 } \\
\hline \multirow[t]{2}{*}{$04 \mathrm{~K}$} & Сpx & 52.04 & 0.85 & 0.21 & 0.11 & 10.76 & 0.44 & 12.68 & 22.81 & 0.17 & 100.07 & 67.7 & 36.1 & 17.2 & 46.7 \\
\hline & Opx & 52.75 & 1.07 & 0.47 & 0.15 & 20.59 & 0.53 & 22.18 & 2.25 & - & 99.99 & 65.8 & 62.7 & 32.7 & 4.6 \\
\hline \multirow[t]{2}{*}{$12 \mathrm{~A} 2$} & Cpx & 51.63 & 2.54 & 0.69 & 0.15 & 9.42 & 0.12 & 13.90 & 21.09 & 0.44 & 99.98 & 72.5 & 40.5 & 15.4 & 44.1 \\
\hline & Opx & 53.28 & 0.96 & 0.26 & 0.07 & 20.86 & 0.39 & 23.00 & 1.45 & 0.16 & 100.43 & 66.3 & 64.3 & 32.7 & 2.9 \\
\hline \multirow[t]{2}{*}{ 12A5 } & Сpx & 52.05 & 2.13 & 0.77 & 0.06 & 9.28 & 0.15 & 13.70 & 22.24 & 0.31 & 100.69 & 72.5 & 39.3 & 14.9 & 45.8 \\
\hline & Opx & 52.96 & 1.07 & 0.34 & 0.10 & 21.26 & 0.31 & 22.52 & 1.88 & 0.17 & 100.61 & 65.4 & 62.9 & 33.3 & 3.8 \\
\hline \multirow[t]{2}{*}{$12 \mathrm{~A} 8$} & Cpx & 51.08 & 2.41 & 1.04 & 0.09 & 9.31 & 0.16 & 13.60 & 21.38 & 0.34 & 99.41 & 72.3 & 39.8 & 15.3 & 44.9 \\
\hline & Opx & 52.93 & 1.12 & 0.54 & - & 20.73 & 0.41 & 22.72 & 1.39 & 0.15 & 99.99 & 66.1 & 64.3 & 32.9 & 2.8 \\
\hline \multirow[t]{2}{*}{$12 \mathrm{~A} 17$} & Cpx & 51.65 & 2.64 & 0.98 & 0.09 & 9.60 & 0.33 & 13.89 & 21.47 & 0.21 & 100.86 & 72.1 & 40.0 & 15.5 & 44.5 \\
\hline & Opx & 52.70 & 0.81 & 0.38 & - & 21.42 & 0.52 & 22.41 & 1.40 & 0.12 & 99.76 & 65.1 & 63.2 & 33.9 & 2.8 \\
\hline \multirow[t]{2}{*}{$12 \mathrm{~A} 21$} & Сpx & 51.43 & 2.54 & 0.84 & 0.20 & 10.65 & 0.18 & 13.46 & 20.86 & 0.41 & 100.57 & 69.3 & 39.1 & 17.4 & 43.5 \\
\hline & Opx & 52.64 & 1.06 & 0.37 & - & 21.68 & 0.35 & 22.18 & 1.48 & - & 99.76 & 64.6 & 62.6 & 34.3 & 3.0 \\
\hline \multicolumn{16}{|c|}{ 角闪辉长岩 } \\
\hline $04 \mathrm{~L}$ & Сpx & 52.54 & 1.26 & 0.13 & 0.10 & 9.83 & 0.37 & 13.53 & 22.42 & 0.30 & 100.48 & 71.0 & 38.5 & 15.7 & 45.8 \\
\hline
\end{tabular}

a) Cpx: 单斜辉石 (clinopyroxene); 全部 $\mathrm{Fe}$ 视为 $\mathrm{FeO} ; \mathrm{Mg} \#: 100 \mathrm{Mg} /\left(\mathrm{Mg}_{\mathrm{Fe}}{ }_{3}^{++}\right) ; \mathrm{Cpx}^{\mathrm{c}}$ : 嵌晶 $\mathrm{cpx}$ 之核部; $\mathrm{Cpx}^{\mathrm{r}}$ : 嵌晶 $\mathrm{cpx}$ 之边部; Opx: 斜方辉 石(orthopyroxene); 全部 $\mathrm{Fe}$ 视为 $\mathrm{FeO}$ 
附录 3 东草河蛇绿岩的代表性斜长石电子探针成分 ${ }^{a)}$

\begin{tabular}{|c|c|c|c|c|c|c|c|c|c|c|c|}
\hline 样本号 & 矿物相 & $\mathrm{SiO}_{2}$ & $\mathrm{Al}_{2} \mathrm{O}_{3}$ & $\mathrm{Fe}_{2} \mathrm{O}_{3}$ & $\mathrm{~K}_{2} \mathrm{O}$ & $\mathrm{CaO}$ & $\mathrm{Na}_{2} \mathrm{O}$ & 总量 & $\mathrm{Ab}$ & An & Or \\
\hline \multicolumn{12}{|c|}{ 钲长质辉长岩 } \\
\hline 11A2 & Plag & 44.88 & 34.84 & 0.33 & 0.00 & 18.60 & 1.05 & 99.70 & 9.3 & 90.7 & 0.0 \\
\hline \multicolumn{12}{|c|}{ 堆晶辉长岩 } \\
\hline 10B2 & Plag & 47.88 & 33.07 & 0.00 & 0.28 & 15.65 & 2.23 & 99.11 & 20.2 & 78.2 & 1.7 \\
\hline 10B3 & Plag & 46.05 & 34.44 & 0.30 & 0.00 & 17.89 & 1.38 & 100.06 & 12.2 & 87.8 & 0.0 \\
\hline 10B5 & Plag & 50.34 & 32.03 & 0.19 & 0.00 & 14.66 & 3.19 & 100.41 & 28.3 & 71.7 & 0.0 \\
\hline 10B7 & Plag & 51.42 & 30.73 & 0.40 & 0.00 & 13.77 & 3.71 & 100.03 & 32.8 & 67.2 & 0.0 \\
\hline 10B13 & Plag & 46.79 & 33.79 & 0.57 & 0.00 & 17.31 & 1.70 & 100.16 & 15.1 & 84.9 & 0.0 \\
\hline $12 \mathrm{~A} 12$ & Plag & 50.74 & 30.69 & 0.33 & 0.11 & 13.64 & 3.68 & 99.19 & 32.6 & 66.8 & 0.6 \\
\hline 12A13 & Plag & 48.33 & 32.54 & 0.47 & 0.00 & 15.78 & 2.48 & 99.60 & 22.1 & 77.9 & 0.0 \\
\hline \multicolumn{12}{|c|}{ 具嵌晶结构之堆晶辉长岩 } \\
\hline 10B6 & Plag & 52.49 & 29.08 & 0.79 & 0.00 & 12.30 & 4.40 & 99.06 & 39.3 & 60.7 & 0.0 \\
\hline \multicolumn{12}{|c|}{ 均质辉长岩 } \\
\hline $04 \mathrm{M}$ & Plag & 51.42 & 30.70 & 0.33 & 0.00 & 13.28 & 4.00 & 99.73 & 35.3 & 64.7 & 0.0 \\
\hline $12 \mathrm{~A} 6$ & Plag & 52.46 & 30.34 & 0.48 & 0.00 & 12.86 & 4.24 & 100.38 & 37.4 & 62.6 & 0.0 \\
\hline $12 \mathrm{~A} 10$ & Plag & 53.02 & 30.00 & 0.38 & 0.00 & 12.54 & 4.50 & 100.44 & 39.4 & 60.6 & 0.0 \\
\hline 12A 14 & Plag & 52.93 & 30.04 & 0.19 & 0.13 & 12.49 & 4.36 & 100.14 & 38.4 & 60.8 & 0.8 \\
\hline \multicolumn{12}{|c|}{ 均质苏长质辉长岩 } \\
\hline $04 \mathrm{~K}$ & Plag & 52.93 & 29.25 & 0.26 & 0.13 & 12.05 & 4.48 & 99.10 & 39.9 & 59.3 & 0.8 \\
\hline $12 \mathrm{~A} 2$ & Plag & 55.11 & 28.85 & 0.47 & 0.14 & 11.34 & 5.16 & 101.07 & 44.8 & 54.4 & 0.8 \\
\hline $12 \mathrm{~A} 5$ & Plag & 51.80 & 29.89 & 0.51 & 0.10 & 12.68 & 4.33 & 99.31 & 38.0 & 61.5 & 0.6 \\
\hline $12 \mathrm{~A} 8$ & Plag & 52.81 & 29.66 & 0.44 & 0.00 & 12.57 & 4.45 & 99.93 & 39.0 & 61.0 & 0.0 \\
\hline $12 \mathrm{~A} 17$ & Plag & 52.46 & 29.95 & 0.30 & 0.16 & 12.54 & 4.27 & 99.68 & 37.8 & 61.3 & 0.9 \\
\hline 12A21 & Plag & 53.06 & 29.75 & 0.27 & 0.00 & 12.30 & 4.47 & 99.85 & 39.7 & 60.3 & 0.0 \\
\hline \multicolumn{12}{|c|}{ 角闪辉长岩 } \\
\hline $04 \mathrm{~L}$ & Plag & 54.95 & 28.64 & 0.29 & 0.00 & 10.81 & 5.45 & 100.14 & 47.7 & 52.3 & 0.0 \\
\hline
\end{tabular}

a) Plag: 斜长石(Plagioclase); $\mathrm{Ab}$ ：钠长石(albite); An：钠长石(anorthite); Or: 钾长石(orthoclase); 全部 $\mathrm{Fe}$ 视为 $\mathrm{Fe}_{2} \mathrm{O}_{3}$ 